\title{
CRISES COMO CATALISADORAS DE CAPACIDADES DE INOVAÇÃO EM GRANDES EMPRESAS: ESTUDO DE CASO DE UMA EMPRESA DE BEBIDAS BRASILEIRA NO CONTEXTO DA COVID-19
}

Maria Teresa Menezes Costa (mariamcosta@ufmg.br) - Universidade Federal de Minas Gerais, UFMG.

Rodrigo Couto Leite Mendes (ㅁodrigoclm@ufmg.br) - Universidade Federal de Minas Gerais, UFMG. Raoni Barros Bagno (raonibagno@ dep.ufmg.br) - Universidade Federal de Minas Gerais, UFMG.

\section{RESUMO}

Fomentar inovações radicais em grandes empresas apresenta diversos desafios e, por isso, essas empresas geralmente desenvolvem mais inovações incrementais. No entanto, em momentos de crise, como a atual pandemia da COVID-19, algumas empresas se destacam por fugir desse padrão. Neste trabalho, por meio de um estudo de caso de uma empresa brasileira do setor de bebidas, será investigado como empresas maduras e de grande porte podem responder rapidamente e de forma inovadora diante de demandas emergenciais causadas pelo contexto de crises. Desdobrando esta questão central, o estudo explora, por meio da análise de dois projetos de inovação, quais ações foram induzidas pelo contexto de crise e que não correspondiam à forma usual de conduzir oportunidades na empresa e em que medida tal contexto contribuiu para a consolidação de capacidades de inovação permanentes na empresa. Palavras chave: gestão da inovação; capacidade de inovação; crise; COVID-19; pandemia. 


\section{INTRODUÇÃO}

A capacidade de inovação é definida por Lawson e Samson (2001, p. 384) como "a capacidade de transformar continuamente conhecimento e ideias em novos produtos, processos e sistemas para o benefício da empresa e de seus stakeholders". É um dos fatores mais importantes para uma empresa se destacar no mercado e sobreviver à competição.

A construção de capacidades de inovação em empresas estabelecidas aparece na literatura como um processo complexo, de difícil articulação e difusão interna, moroso e até mesmo improvável, principalmente tratando-se de inovação radical. Ao passo em que as inovações incrementais permitem que as empresas sustentem suas vantagens competitivas no curto prazo e em condições de estabilidade, as inovações radicais se fazem necessárias para estimular a atmosfera criativa e prolongar a vantagem competitiva através de novos produtos, processos e métodos de gestão.

Em contraponto, alguns estudos e informações disponíveis publicamente relatam o desenvolvimento de iniciativas inovadoras em empresas estabelecidas quando imersas num contexto atípico causado por grandes crises, como é o caso contemporâneo das situações advindas da COVID-19. Na Itália, por exemplo, no contexto da falta de aparelhos respiradores, a empresa Isinnova, que apoia outras empresas na exploração de suas capacidades de inovação, trouxe uma ideia para a Decathlon atuar no problema. Em questão de horas, eles compartilharam os detalhes necessários para projetar as novas válvulas para sua máscara de mergulho (VESCI et al., 2021) e, a partir disso, foi possível conter a falta de equipamento nos hospitais italianos.

Os pontos acima nos levam à seguinte questão central de pesquisa: como empresas maduras e de grande porte, que apresentam usualmente dificuldades para propor e conduzir inovações substantivas, podem responder rapidamente às demandas emergenciais dos contextos de crise? Desdobrando esta questão central, o estudo pretende, por meio da análise de dois projetos de inovação disparados pelo contexto de crise, identificar ações associadas a inovação induzidas por tal contexto e em que medida estas iniciativas apontam para a consolidação de rotinas e/ou capacidades de inovação permanentes na empresa.

Nesta investigação aprofundamos no caso de uma empresa do setor de bebidas que utilizou suas competências para atuar diretamente na crise causada pela pandemia da COVID19. No período de março a setembro de 2020, a empresa usou o etanol de suas cervejarias 
para produzir álcool em gel e mobilizou seus funcionários para construir um hospital em parceria com empresas de outros setores e com a prefeitura da cidade.

\section{REVISÃO TEÓRICA}

\subsection{Desafios da Inovação em Grandes Empresas}

Inovação é a introdução de um produto ou processo novo ou significativamente aprimorado que se difere de produtos e processos anteriores e que requer um grau expressivo de novidade para uma empresa (OECD; EUROSTAT, 2018).

As empresas com capacidade incremental de inovação têm competência para entregar inovações de produto que se afastem minimamente das rotinas, operações e conhecimento existentes. Em contrapartida, as empresas que possuem capacidade de inovação substantiva são capazes de entregar algo que é significativamente diferente em relação a suas ofertas e processos atuais, pois podem envolver tecnologias inovadoras e benefícios para o cliente que alteram drasticamente a forma como os produtos são usados e experimentados (CHANDY; TELLIS, 1998, 2000).

A inovação substantiva é um fenômeno em que a promessa da oportunidade é muito grande ao mesmo tempo em que o seu risco e a sua incerteza são altos (LEIFER; O'CONNOR; RICE, 2002; MORONE, 1993). Nesse contexto, Leifer, O’Connor e Rice (2002) afirmam que a inovação incremental é capaz de manter as grandes empresas competitivas no curto prazo, mas que, para o crescimento a longo prazo, apenas sua capacidade mais radical (aqui denominada como substantiva) possui tal aptidão.

Uma percepção comum no campo da inovação é que as grandes empresas estabelecidas raramente introduzem inovações radicais. Chandy e Tellis (2000) sugerem três razões pelas quais as grandes empresas podem resistir em introduzir essas inovações: incentivos percebidos, filtros organizacionais e rotinas organizacionais. Grandes empresas têm um incentivo menor para desenvolver ou comercializar inovações radicais no curto prazo, possuem estruturas cognitivas que filtram informações focar sua atenção em suas prioridades e rotinas organizacionais mais voltadas para o desenvolvimento de inovações incrementais.

Um outro ponto é que, conforme as empresas crescem, elas ficam sujeitas às forças da inércia burocrática (TORNATZKY; FLEISCHER, 1990) e o principal fator que contribui para essa inércia é o número grande de funcionários que trabalham nessas companhias. Com isso, os funcionários inovadores muitas vezes precisam atravessar camadas administrativas de resistência burocrática para obter aprovação para suas ideias e o processo aumenta a 
probabilidade de seleção de ideias radicais, inibindo uma atmosfera criativa (KAMIEN; SCHWARTZ, 1975) e se tornando menos flexíveis do que empresas menores (COHEN; KLEPPER, 1996).

Por último, em grandes empresas, uma vez conhecido o modelo de negócios, passam a se organizar em torno de indicadores e metas. Paradoxalmente, esse direcionamento limitado aos próprios indicadores e processos, que tornam as empresas eficientes, são a causa raiz da incapacidade de serem inovadoras ágeis e responsivas (BLANK, 2014).

Portanto, uma vez que a capacidade de inovação se dá pela força ou a proficiência de um conjunto de práticas organizacionais para o desenvolvimento de novos produtos ou processos (PENG; SCHROEDER; SHAH, 2008), nas grandes empresas ela está intimamente relacionada à capacidade de aproveitar o conhecimento que possuem (SUBRAMANIAM; YOUNDT, 2005) e combiná-los com outros conhecimentos externos (YLI-RENKO; AUTIO; SAPIENZA, 2001) para confrontar as objeções de suas conjunturas. O processo de inovação nas empresas é um processo de acumulação e criação de novos conhecimentos (NONAKA; TAKEUCHI, 1995, ZAHRA; GEORGE, 2002) e o desempenho desse processo depende criticamente da capacidade da empresa de gerenciar o conhecimento e as práticas de recursos humanos que utiliza (CHEN; TSOU; HUANG, 2009). A inovação é construída em atividades de compartilhamento de conhecimento coletivo e interação frequente entre diferentes indivíduos e grupos (GOLD; MALHOTRA; SEGARS, 2001).

\subsection{O Papel Catalisador das Crises na Inovação em Empresas}

$\mathrm{Na}$ literatura atual, não existe um consenso a respeito do papel catalisador das crises na inovação. Para alguns autores, como Bessant, Rush e Trifilova (2015, p.2), “crises, sejam naturais ou provocadas pelo homem, exigem uma solução rápida de problemas [...]; inovação neste contexto costuma ser uma questão de vida ou morte." Enquanto isso, para outros, principalmente quando se trata de crises financeiras, os efeitos na inovação podem ser negativos, devido à redução da demanda e dos incentivos financeiros e do aumento do risco de crédito (OECD, 2018).

Um exemplo marcante de crise que demandou rápida atuação inovadora em todas as partes do mundo é a pandemia da COVID-19. Na Itália, aparelhos respiradores estavam em falta quando médicos acionaram outros setores para pensarem em uma solução. Nesse contexto, a Isinnova, empresa com foco em apoiar outras empresas e organizações na exploração de suas capacidades de inovação, trouxe a ideia de imprimir as máscaras em 
impressoras 3D para a Decathlon. Em questão de horas, eles compartilharam os detalhes necessários para projetar as novas válvulas para sua máscara de mergulho (VESCI et al., 2021) e, a partir disso, foi possível conter a falta de equipamento nos hospitais italianos.

Entretanto, os aspectos trazidos por esta pandemia já foram observados anteriormente em outros momentos de crise. Um caso semelhante ocorreu durante a epidemia de Ebola, doença que atingiu diversos países africanos em 2014. A IBM, por exemplo, usou seu laboratório de pesquisa na África para ajudar a população a informar ao governo suas percepções individuais. Os dados foram todos rastreados por localização, permitindo que a IBM criasse "mapas de calor baseados em opinião", ajudando a estabelecer um sistema unificado para rastrear a progressão do vírus conforme ele se espalha (STURGIS, 2014).

Ademais, é necessário ser crítico em relação à atuação das empresas no momento de crise para identificar se o impulso gerado não tem caráter apenas pontual. Caso as inovações decorrentes da crise sejam meramente reações às condições adversas, dificilmente ocorrerão no futuro exemplos semelhantes aos gerados neste cenário. O processo de inovação requer o acesso e a análise de informações e, mais do que isso, demanda projeções do futuro, adaptações na operação e nos modelos de negócios para mudar rápido e inovar sempre (PEREIRA; MENEZES, 2020).

\section{METODOLOGIA}

Tendo em vista o referencial apresentado anteriormente e outras fontes na literatura, os conceitos importantes para o desenvolvimento deste trabalho foram sintetizados no mapa conceitual disposto na Figura 1. Um estudo de caso como o aqui proposto tem como objetivo analisar uma ou mais situações ocorridas pontualmente, mas que possuem características que possam ser replicadas em outros cenários. Sendo a questão central deste estudo voltada para inovação em grandes empresas, o mapa foi dividido em três frentes que orientam a análise: vantagens que potencializam a inovação, barreiras que dificultam e o contexto de crise como catalisador de inovação. O mapa contempla referências consideradas em uma versão mais ampla do estudo e que não estão citadas nesta versão do texto por questões de síntese. Cada frente possui argumentos que embasam, por meio do ponto de vista de diferentes autores, a sua relevância para a capacidade inovativa das grandes empresas. 


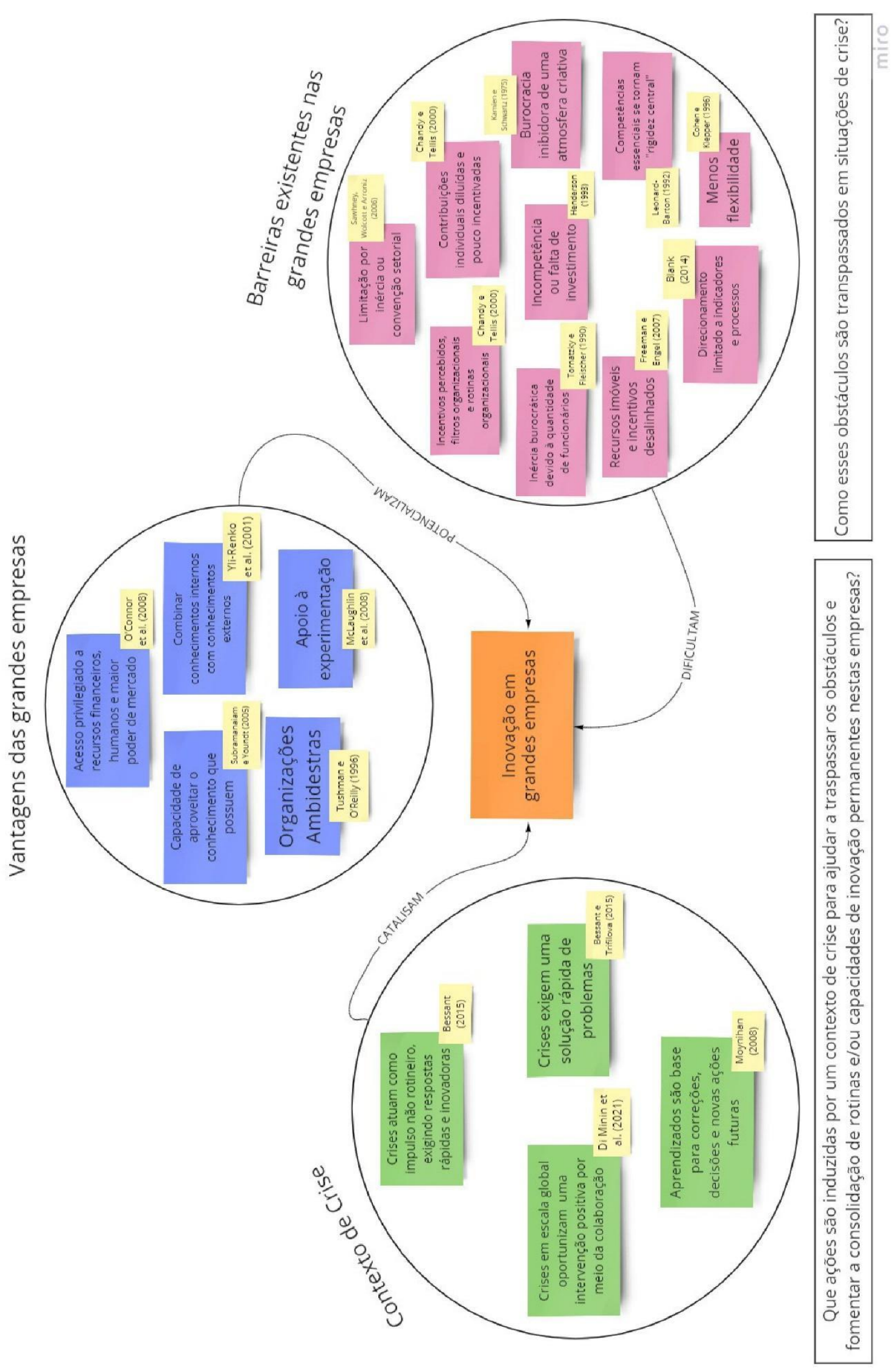

Figura 1: Mapa conceitual do trabalho. Fonte: Os autores. 
O estudo foi realizado no contexto de uma cervejaria de grande porte e focou em dois projetos, a produção de álcool em gel com o insumo retirado da cerveja sem álcool e a expansão de um hospital da rede pública, motivados pelo contexto da pandemia de COVID19. A escolha do caso deu-se em razão à relevância no cenário brasileiro frente a uma realidade nunca vista anteriormente. Outro ponto relevante para a escolha da empresa foi a abertura para obter-se informações pertinentes ao estudo. Partindo de questões guiadas pelo mapa conceitual da figura 1, foram entrevistados seis envolvidos nos projetos à luz de suas experiências nas iniciativas, percepções sobre o ambiente organizacional e elementos constituintes de uma capacidade de inovação. O perfil dos entrevistados variou, desde os cargos até ao ambiente de trabalho: dois diretores, um gerente de projetos e um estagiário no nível corporativo e um coordenador e um analista na fábrica onde foi produzido o álcool em gel. Em relação ao tempo de experiência, os diretores possuem cerca de 10 anos de empresa, o gerente, o coordenador e o analista 6 anos e o estagiário menos de 2 anos. Cada entrevista durou entre trinta minutos e uma hora. Todo o material foi gravado e transcrito para apoio à etapa de análise.

Preliminarmente ao trabalho, foram coletados dados secundários de acesso público relativos aos projetos por meio de websites, reportagens, podcasts e entrevistas concedidas a outras organizações. As informações coletadas nas entrevistas foram agrupadas por afinidade entre entrevistas distintas e posteriormente informações convergentes e complementares foram associadas às dimensões típicas da capacidade de inovação. A partir das argumentações dos entrevistados, buscou-se continuamente distinguir aspectos pontuais ocorridos no projeto com outros que foram percebidos como legados permanentes e, portanto, associáveis a uma capacidade de inovação na forma de recursos disponíveis para outras iniciativas presentes e futuras da empresa.

\section{RESULTADOS E DISCUSSÃO}

Com a propagação da COVID-19 pelo mundo, diversas companhias se mobilizaram para pensar em iniciativas para amenizar os efeitos da crise causada pelo novo coronavírus. No Brasil, a cervejaria sobre a qual se desenvolveu o presente estudo se destacou pela agilidade em anunciar a produção de álcool em gel, que seria distribuído aos hospitais públicos de diversas cidades, e a construção de um hospital para tratamento da COVID-19, o qual passaria a integrar a rede pública de saúde da cidade de São Paulo. 
O processo de produção do álcool em gel aconteceu nas fábricas da empresa, que realizaram a purificação do álcool que vem do processo cervejeiro. Com a ajuda de um parceiro, o álcool líquido foi transformado em gel, e posteriormente engarrafado e distribuído para as secretarias de saúde. Já no projeto de construção do hospital, a empresa realizou a gestão do projeto e arcou com os custos, contando com a técnica de construção e a gestão hospitalar dos parceiros que, juntos, possibilitaram a entrega da unidade de saúde com cem leitos num prazo menor que o previsto.

Essas iniciativas foram escolhidas para a realização deste estudo de caso, uma vez que os produtos dos projetos se diferem completamente de qualquer outro já executado pela empresa, comprovando a realização de inovações substantivas conforme a definição do Manual de Oslo (OECD; EUROSTAT, 2018). Analisando cada projeto de inovação, notam-se individualidades e pontos compartilhados por ambos. A ideia da produção do álcool em gel, por exemplo, partiu de uma reunião executiva do time global com os diretores brasileiros, como pode-se perceber na fala de um dos diretores entrevistados: "eles viraram pra gente e perguntaram "vocês não acham que vocês podem fazer isso?". Por outro lado, a do hospital foi ideia de uma gerente de projetos. Um fornecedor da empresa estava mostrando as novidades de construção modular para ela quando pensou: "dá para fazer um hospital”. No entanto, mesmo os entrevistados do primeiro projeto afirmaram que a maioria das ideias ocorrem de baixo para cima e partem da colaboração de diversas pessoas. O diretor entrevistado disse que "são ideias que nascem do grupo e do momento" e a gerente de projetos afirmou que "nunca é a ideia de alguém, é sempre um grupo, é muito colaborativo".

A relação com parceiros também foi bem diferente, já que no projeto de álcool em gel a produção foi feita toda dentro da cervejaria com recursos da própria empresa e no caso do hospital as parcerias com uma construtora, uma gestora de hospitais e uma fornecedora de materiais foram vitais para que o projeto ocorresse. A gerente de projetos responsável pela construção do hospital disse que contou com a expertise dos parceiros durante todo o processo:

"Eu não conseguiria definir o equipamento, a intervenção elétrica que a gente faz na cervejaria não funciona no hospital. Até nisso a gente contou com a ajuda deles, um negócio desse tamanho a gente não pode fazer sozinho."

Em relação aos pontos em comum, tem-se a mão de obra para a execução dos projetos como um exemplo, já que para ambos não houve um problema crítico de alocação, devido à redução de demanda de trabalho no período de crise. Outro ponto foi a agilidade de execução 
e a atuação no momento preciso da necessidade. O projeto de álcool em gel foi desenvolvido em sete dias, num cenário crítico em que esse produto, fundamental para reduzir a propagação do vírus, já que estava em falta em todo o país. Já o hospital foi construído em 34 dias, tempo recorde no Brasil, em um momento em que o mundo inteiro começava a falar em superlotação e falta de leitos. Como conta um dos entrevistados:

"Quando a gente começou, não tinha nenhum caso de covid em São Paulo na rede pública. Quando apareceu o primeiro foi lá (nesse hospital) e a gente já tinha uma semana de obra."

Nos dois projetos a comunicação se mostrou primordial. Ambos fizeram reuniões diárias com todo o time envolvido para alinhamento e tomadas rápidas de decisão e tanto nas entrevistas sobre o álcool em gel quanto nas do hospital foi enfatizado o poder do uso de metodologias e ferramentas de projeto que já funcionavam dentro da empresa, como o uso de dashboard para acompanhamento de indicadores e a aplicação do Scrum como abordagem de gestão.

Por outro lado, a realização dos projetos também apresentou caminhos alternativos aos que a empresa está acostumada para desenvolver suas iniciativas. Depender da expertise e incorporar elementos da cultura de outras empresas parceiras foram novas formas desafiadoras para conseguir executar e entregar os projetos, segundo os entrevistados. Outro ponto importante na adaptação da forma de trabalho da empresa foi a necessidade de orientação constante dos envolvidos. Segundo a gerente de projetos, diferente da autonomia com a qual os funcionários da cervejaria estão acostumados a trabalhar, para entregar o projeto no curto prazo foi fundamental o acompanhamento diário e as cobranças pontuais sobre as ações a serem executadas para que o cronograma fosse cumprido num contexto de tamanha urgência, ao qual se aplicam abordagens ágeis de desenvolvimento de projetos.

Por fim, respondendo aos questionamentos propostos pelo mapa conceitual, as ações induzidas pelo contexto da pandemia para ajudar a transpassar os obstáculos e a fomentar a consolidação de rotinas e/ou capacidades de inovação permanentes neste caso foram a urgência de ação e a própria necessidade de mudança percebida de forma abrangente na empresa.

A urgência se deu pela rapidez em que a doença se espalhou pelo mundo, trazendo novas demandas que nenhum dos setores da economia estava preparado. Como essas demandas não eram naturalmente atendidas pela empresa analisada, foram então desdobradas maneiras de contribuir para conter a situação. Conforme afirmado por todos entrevistados, 
esse auxílio também foi consequência dos valores da empresa, que já tinha atuado em situações de crise anteriores, como a falta de água após o rompimento da barragem de Brumadinho, em Minas Gerais.

Já a necessidade de mudança se deu porque o setor da empresa foi afetado pela pandemia e as vendas caíram muito, deixando alguns funcionários ociosos e algumas áreas paralisadas. A partir de um olhar de longo prazo, os executivos da empresa perceberam que quanto piores forem as consequências da pandemia para o país, piores seriam os efeitos para a própria empresa, já que cerveja não é um item básico de consumo e com certeza seria cortado da lista de muitos brasileiros na perspectiva de altos níveis de desemprego e de inflação. Dessa forma, se a empresa não mudasse sua forma de atuar frente à nova realidade, o resultado poderia ser irreversível.

Como resposta à segunda pergunta chave, esses obstáculos foram transpassados por meio de parcerias, de mudanças em processos e de engajamento da liderança. As parcerias ajudaram a empresa a extrapolar suas próprias capacidades para resolver os problemas mais urgentes. A mudança dos processos deu autonomia para os funcionários e encurtou a distância entre hierarquias, além de diminuir o tempo da tomada de decisão. Finalmente, o engajamento da liderança deu espaço àqueles que tivessem ideias de apresentá-las, com a possibilidade de materializá-las; tornou os projetos relevantes tanto interna quanto externamente; e garantiu os recursos necessários para que as ideias com maior potencial tivessem condições de avançar para a execução.

Dessa forma, os casos reforçam a ideia de que é possível às grandes empresas traspassarem barreiras típicas à inovação comumente debatidas na literatura, inclusive de forma bastante acelerada, e que as experiências concretas proporcionadas por projetos dessa natureza atuam como um importante laboratório de aprendizagem e experimentação de novas abordagens, já que desfrutam de um certo grau de proteção gerencial para que atendam o contexto de crise disparador. Cabe às empresas, então, consolidar esse aprendizado, transformando-o em recurso aplicável a outros contextos e projetos.

\section{CONCLUSÃO}

Tomando como referência o presente estudo de caso e outras referências da literatura, é possível afirmar que as crises são capazes de exercer um papel catalisador de inovações em grandes empresas. Ainda não está evidente se esses elementos serão mantidos no momento pós crise, mas já se observa que muitas características consideradas inibidoras de inovações 
radicais dentro de grandes empresas foram completamente transformadas para uma rápida resposta à pandemia da COVID-19. Na empresa em que o estudo foi realizado, observamos uma transformação da atmosfera inovadora, tornando-a mais inclusiva e favorável a iniciativas que demandam agilidade e proatividade, como reforça o relato de um dos entrevistados:

"Inicialmente eram pessoas que queriam fazer algo de diferente, nesse caso os diretores da empresa. Quando eles viram que deu certo, eles perceberam que aquilo era o futuro da companhia e estão construindo um ambiente aberto para que qualquer pessoa da companhia possa levar ideias e projetos para serem aprovados."

Para continuidade do estudo torna-se necessário aguardar um período posterior à crise para fazer uma avaliação e identificar se as competências inovadoras da empresa em questão foram de fato modificadas.

\section{REFERÊNCIAS}

BESSANT, J.; RUSH, H.; TRIFILOVA, A. Crisis-driven innovation: the case of humanitarian innovation. International Journal of Innovation Management, v. 19, n. 06, p. $1-17,2015$.

BLANK, S. Why companies are not startups. Retrieved May, v. 20, p. 2015, 2014.

CHANDY, R. K.; TELLIS, G. J. Organizing for radical product innovation: the overlooked role of willingness to cannibalize. Journal of Marketing Research, v. 35, n. 4, p. 474-487, 1998.

CHANDY, R. K.; TELLIS, G. J. The Incumbent's curse? Incumbency, size, and radical product innovation. Journal of Marketing, v. 64, n. 3, p. 1-17, 2000.

CHEN, J.; TSOU, H.; HUANG, A. Service delivery innovation: antecedents and impact on firm performance. Journal of Service Research, v. 12, n. 1, p. 36-55, 2009.

COHEN, W. M.; KLEPPER, S. A Reprise of size and r\&d. The Economic Journal, v. 106, n. 437, p. 925-951, 1996.

GOLD, A. H.; MALHOTRA, A.; SEGARS, A. H. Knowledge management: an organizational capabilities perspective. Journal of Management Information Systems, v. 18, n. 1, p. 185-214, 2001.

KAMIEN, M. I.; SCHWARTZ, N. L. Market structure and innovation: a survey. Journal of Economic Literature, v. 13, n. 1, p. 1-37, 1975.

LAWSON, B.; SAMSON, D. Developing innovation capability in organizations: a dynamic capabilities approach. International Journal of Innovation Management, v. 5, n. 03, p. 377-400, 2001.

LEIFER, R.; O'CONNOR, G. C.; RICE, M. A Implementação de inovação radical em empresas maduras. Revista de Administração de Empresas, v. 42, n. 2, p. 17-30, 2002.

MORONE, J. Winning in high tech markets. Boston: Harvard Business School Press, 1993. 
NONAKA, I.; TAKEUCHI, H. The Knowledge-creating company: How Japanese companies create the dynamics of innovation. Oxford University Press, 1995.

O'REILLY, C. A.; TUSHMAN, M. L. The Ambidextrous organization. Harvard Business Review, v. 82, n. 4, p. 74-83, 2004.

OECD/EUROSTAT. Oslo manual 2018: guidelines for collecting, reporting and using data on innovation. 4th ed. Paris: The Measurement of Scientific, Technological and Innovation Activities, OECD; Luxembourg: $\quad$ Eurostat, $2018 . \quad$ DOI: https://doi.org/10.1787/9789264304604-en.

PENG, D. X.; SCHROEDER, R. G.; SHAH, Rachna. Linking routines to operations capabilities: a new perspective. Journal of Operations Management, v. 26, n. 6, p. 730-748, 2008.

PEREIRA, H.; MENEZES, H. O Que Permanece e o que muda para a inovação? Innovation Insights, p. 6, 2020.

STURGIS, K. How The Ebola crisis has sparked innovation. Medical Device and Diagnostic Industry News, 2014. Disponível em: https://www.mddionline.com/digital-health/howebola-crisis-has-sparked-innovation. Acesso em: 31 mar. 2021.

SUBRAMANIAM, M.; YOUNDT, M. A. The Influence of intellectual capital on the types of innovative capabilities. Academy of Management Journal, v. 48, n. 3, p. 450-463, 2005.

TORNATZKY, L. G.; FLEISCHER, M.; CHAKRABARTI, A. K. Processes of Technological Innovation. Lexington books, 1990.

VESCI, M.; FEOLA, P.; PARENTE, R.; RADJOU, N. How to save the world during a pandemic event. A case study of frugal innovation. R\&D Management, Feb.2021. DOI: https://doi.org/10.1111/radm.12459.

YLI-RENKO, H.; AUTIO, E.; SAPIENZA, H. J. Social capital, knowledge acquisition, and knowledge exploitation in young technology-based firms. Strategic Management Journal, v. 22, n. 6-7, p. 587-613, 2001.

ZAHRA, S.; GEORGE, G. Absorptive capacity: a review, reconceptualization, and extension. The Academy of Management Review, v. 27, n. 2, p. 185, 2002. 